\title{
SABERES TRADICIONAIS COMO PATRIMÔNIO CULTURAL IMATERIAL DINAMIZADOR DO DESENVOLVIMENTO SUSTENTÁVEL
}

TRADITIONAL KNOWLEDGE AS INTANGIBLE CULTURAL HERITAGE AND A FACILITATOR OF SUSTAINABLE DEVELOPMENT

LOS SABERES TRADICIONALES COMO PATRIMONIO CULTURAL INMATERIAL DINAMIZADOR DEL DESARROLLO SOSTENIBLE

Márcia Rodrigues Bertoldi ${ }^{1}$

Resumo: O presente trabalho analisa a proteção dos conhecimentos tradicionais das comunidades tradicionais, associados ao uso da biodiversidade, a partir de um marco teórico jurídico, apresentando e discutindo alguns possíveis instrumentos para o resguardo desses saberes tradicionais, não raras vezes ancestrais, transmitidos oralmente de geração em geração e que constituem um patrimônio cultural imaterial capaz de instrumentalizar o desenvolvimento

sustentável.

Palavras-chave: biodiversidade; conhecimentos tradicionais associados; direito socioambiental; multiculturalism

\footnotetext{
${ }^{1}$ Doutora em Direito pela Universidade de Girona e Universidade Pompeu Fabra. Professora na Universidade Federal de Pelotas. E-mail: marciabertoldi@yahoo.com.
} 
Abstract: The current assay analyzes the protection of the knowledge of traditional communities and other local traditional ones, which have been related to the use of the biodiversity, from a legal mark. Thus, this assay presents and discusses some possible instruments for guarding such traditional knowledge, often ancestors, orally transmitted from generation to generation, and therefore considered as an immaterial cultural heritage able to instrumentalize the sustainable development.

Keywords: biodiversity; traditional knowledge; socioenvironmental Law; multiculturalism.

Resumen: El presente trabajo analiza la protección de los conocimientos tradicionales de las comunidades tradicionales, asociados al uso de la biodiversidad, a partir de un marco teórico jurídico, presentando y discutiendo algunos posibles instrumentos para lo resguardo de eses saberes tradicionales, no pocas veces ancestrales, transmitidos oralmente de generación en generación y que constituye un patrimonio cultural inmaterial capaz de instrumentalizar el desarrollo sostenible.

Palabras clave: biodiversidad; conocimientos tradicionales asociados; derecho social ambiental; multiculturalismo.

\section{INTRODUÇÃO: A SOCIO E BIODIVERSIDADE}

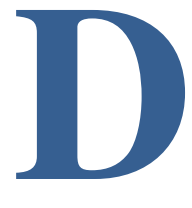

Desde o surgimento da escrita, em torno de 4000 aC, a humanidade procura empregar mecanismos eficazes a fim de registrar seus pensamentos, suas ações, crenças, lembranças. De todas as informações geradas em um determinado tempo histórico, somente constituem a cultura aquelas que tenham sido de alguma ou outra forma 
arquivadas, conservadas e/ou transmitidas, adquirindo a capacidade de contribuir para o estabelecimento do que se convenciona como memória social ou coletiva ${ }^{2}$ ou patrimônio cultural imaterial: uma informação legada que retro-alimenta e avança, provoca sentidos, ressemantizações, subsiste aos tempos e espaços que lhe são específicos.

Uma das inumeráveis memórias coletivas são os conhecimentos ou saberes tradicionais ${ }^{3}$ associados à biodiversidade, os conhecimentos, as inovações e práticas consuetudinárias que usam recursos da biodiversidade. Em sua maioria, tais conhecimentos, pertencentes a comunidades tradicionais, encontram-se nos denominados países megadiversos, aqueles que possuem grande concentração de espécies da flora, fauna e ecossistemas do planeta ( $70 \%$ do total).

Durante séculos, estes povos sofreram incontáveis expropriações e com isso perderam, para as indústrias farmacêutica, de cosméticos, agrícola, entre outras, seus conhecimentos milenários e intergeracionais acerca de como utilizar e transformar um recurso em bem ou serviço ao ser humano e à natureza. Assim, sofreram e sofrem impactos culturais, sociais, econômicos e ambientais sobre suas leis, que não existem por escrito, que não são ditadas por um poder.

Com a entrada em vigor da Convenção sobre a diversidade biológica (CDB) em 1993 o peculiar predicado desses saberes desfrutou de um horizonte de possibilidade de proteção jurídica. Resulta que por primeira

\footnotetext{
${ }^{2} \mathrm{O}$ sentimento de pertença a um grupo não pressupõe a presença atual de seus membros. Suas influências podem permanecer vivas, orientando o olhar do memorialista sobre o passado. Ainda assim, o apoio coletivo à memória é mais vigoroso quando envolve a presença sensível de antigos companheiros e suas marcas no entorno. A materialidade como que incrementa a presença do grupo em pensamento. A convivência entre antigos companheiros nutre a comunicação entre visões de mundo que se limitam, se conformam e se interpenetram. O passado permanece então em contínua reconstrução pela memória coletiva (FROCHTENGARTEN, Fernando. "A memória oral no mundo contemporáneo". In: Estudos Avançados. Vol. 19. N. 55. São Paulo: setembro/dezembro, $2005 . \quad$ Disponível em: http://www.scielo.br/scielo.php?script=sci_arttext\&pid=S0103-40142005000300027\&lang=pt

3 Manuela Carneiro da Cunha entende e utiliza a expressão "saber local porque, a meu ver, embora a expressão englobe a de saber tradicional ou de saber indígena, ela se presta menos a confusões. A escolha dos termos não é fortuita. Saber local, como aliás qualquer saber, refere-se a um produto histórico que se reconstrói e se modifica, e não a um patrimônio intelectual imutável, que se transmite de geração a geração". DA CUNHA, Manuela Carneiro. "Populações tradicionais e a Convenção da Diversidade Biológica". In: Estudos Avançados. Vol. 13. №. 36. São Paulo:maio/agosto de 1999. Disponível em: http://www.scielo.br/scielo.php?script=sci_arttext\&pid=S0103-40141999000200008\&lang=pt
} 
vez na esfera jurídica internacional, os conhecimentos tradicionais receberam o devido reconhecimento e proteção, tanto no preâmbulo como em artigo próprio (8j).

No preâmbulo, a CDB proclama a estreita dependência dos recursos biológicos aos conhecimentos tradicionais em se tratando da conservação e utilização sustentável da biodiversidade e no artigo 8j incita os Estados Parte a respeitar, preservar e manter estes saberes, bem como a criar mecanismos para repartir justa e equitativamente os benefícios derivados do uso, o que abrange um sistema de direitos de propriedade intelectual.

Em 2003, uma vez mais esses saberes foram olhados juridicamente. A Convenção para a salvaguarda do patrimônio cultural imaterial contempla os saberes tradicionais associados à biodiversidade e promove o respeito à diversidade cultural e à criatividade humana.

Ademais, o Estado brasileiro, desde 1988 com a promulgação da Constituição Federal, vem cumprindo com o dever de tutela, ao menos em previsão legal. Enquanto o artigo 215 protege as manifestações culturais, o 216 elenca os componentes do patrimônio cultural, material e imaterial.

O presente trabalho analisa a proteção dos conhecimentos tradicionais das comunidades tradicionais, associados ao uso da biodiversidade, a partir de um marco teórico jurídico, apresentando e discutindo alguns possíveis instrumentos para o resguardo desses saberes, não raras vezes ancestrais, transmitidos oralmente de geração em geração e que constituem um patrimônio cultural imaterial capaz de instrumentalizar o desenvolvimento sustentável.

\section{OS COMPONENTES QUE ENVOLVEM O TEMA: A BIODIVERSIDADE E OS CONHECIMENTOS TRADICIONAIS ASSOCIADOS}

O conceito de biodiversidade ou diversidade biológica compreende três elementos objetivos ou dimensões: a diversidade de espécies da fauna, da flora e de microorganismos, a diversidade de ecossistemas e a 
diversidade genética dentro de cada espécie, ou patrimônio genético. A este conceito se soma um elemento adjetivo, o conhecimento tradicional das comunidades tradicionais (indígenas, quilombolas, ribeirinhos, caiçaras, seringueiros, pescadores, entre outros). Nesse sentido, "o conceito abrange uma quarta dimensão, a cultural, representada pelos valores, visões de mundo, conhecimentos e práticas que têm íntima relação com o uso direto e os processos relacionados à biodiversidade" ${ }^{4}$.

Pode-se afirmar que a biodiversidade é a total variedade de espécies, seus genes e ecossistemas do Planeta, os quais constituem uma das propriedades fundamentais do meio ambiente e do equilíbrio da biosfera, assim como das relações entre todos os seres vivos, visto que seus componentes formam um processo sistêmico ou holístico da vida. É fonte de desenvolvimento humano mediante as atividades agrícola, pesqueira, florestal, e sobretudo da indústria biotecnológica.

Assim, pode ser definida como a vida sobre/na/da Terra e o bem mais valioso, junto à água, que dispomos. Este valor é o resultado dos aspectos ecológico, social, econômico, científico, cultural, histórico, geológico, espiritual, recreativo e estético que compõem esse elemento ambiental.

Como antes dito, à biodiversidade se soma um elemento adjetivo, imaterial ou intangível e essencial à sua conservação e uso sustentável: o conhecimento, inovações e práticas tradicionais das comunidades tradicionais. Esse elemento compreende:

desde técnicas de recursos naturais até métodos de caça e pesca, conhecimentos sobre os diversos ecossistemas e sobre propriedades farmacêuticas, alimentícias e agrícolas de espécies e as próprias categorizações e classificações de espécies de flora e fauna utilizadas pelas populações tradicionais ${ }^{5}$.

Também, se refere ao extrativismo, uso e conhecimento de fibras, sementes, óleos, resinas; ao conhecimento e manejo do solo, da água e sua

\footnotetext{
${ }^{4}$ SOUZA, Gabriela Coelho de, et. al. "Conhecimentos tradicionais: aspectos do debate brasileiro sobre a quarta dimensão da biodiversidade". In: KISHI, Sandra Akemi Shimada; KLEBA, John Bernhard. Dilemas do acesso à biodiversidade e aos conhecimentos tradicionais. Direito, Política e Sociedade. Belo Horizonte: Método, 2009, p. 72.

${ }^{5}$ SANTILLI, Juliana. Socioambientalismo e Novos Direitos. São Paulo: Peirópolis, 2005, p. 192.
} 
função; a tecnologias de feitura de casas, instrumentos de trabalho; ao conhecimento sobre os astros, planetas, satélites e sua relação com as práticas espirituais e místicas; à produção artística e visão estética originárias do uso de recursos naturais, tais como tinturas, cerâmicas, etc. ${ }^{6}$. Em suma, um amplo conhecimento do mundo natural e sobrenatural.

Mas talvez este saber seja utilitariamente marcante na indústria farmacêutica. É sabido que o mercado de medicinas é um usuário em potencial de recursos biológicos e, consequentemente, de conhecimentos, práticas e inovações relacionados ao uso da biodiversidade gerados por comunidades tradicionais. Estima-se que $40 \%$ dos remédios derivam de fontes naturais. Entre inúmeros exemplos, podemos citar uma proteína extraída da enzima de uma rã (Phyllomedusa oreades) que vive no cerrado brasileiro e que pode ser a chave para a cura do mal de Chagas.

Cabe entender que são sistemas que evoluíram simultaneamente, o biológico e o cultural'; portanto, não se pode conceber conhecimentos tradicionais e biodiversidade senão que sistemicamente. São sistemas inseparáveis, complementares, organizados e dinâmicos: mais do que nunca a natureza não pode ser separada da cultura e precisamos aprender a pensar transversalmente as interações entre ecossistemas, mecanosfera e Universos de referências sociais e individuais ${ }^{8}$.

Essas comunidades, povos ou sociedades tradicionais, guardiãs de um rico saber, compartem estilos de vida particulares, fundados na natureza, no conhecimento sobre ela e nas melhores práticas para conservá-la e utilizá-la sustentavelmente, respeitando desse modo sua capacidade de recuperação

\footnotetext{
${ }^{6}$ DIEGUES, Antônio Carlos e ARRUDA, Rinaldo S, V. (orgs.) Saberes Tradicionais no Brasil. Brasília: Ministério do Meio Ambiente; São Paulo: USP, 2001., p. 71.

7 Explica Flores que o processo cultural coincide com o processo de humanização, tanto da natureza humana (imaginário social e imaginário radical) como da natureza física e social (imaginário ambiental bio-socio-diverso) no marco de uma consideração relacional do conceito de meio ambiente. Através da construção cultural nos humanizamos, isto é, vamos adquirindo a capacidade de explicação, de interpretação e de transformação/adaptação do conjunto de relações que mantemos com os outros, com nós mesmos e com a natureza (FLORES, Joaquín Herrera. Cultura y naturaleza: La construcción del imaginário ambiental bio(sócio)diverso. In Hiléia. Revista de Direito Ambiental da Amazônia. Ano 2. Número 2. Janeiro-junho de 2004. Manaus: Edições Governo do Estado do Amazonas / Secretaria de Estado de Cultura / Universidade do Estado do Amazonas, 2004, p. 43. (tradução da autora)

${ }^{8}$ GUATTARI, Félix. As três ecologias. 6 a Ed. São Paulo: Papirus, 1997, p. 25.
} 
e conservação. Diferentemente das sociedades capitalistas ${ }^{9}$, pouco cobiçam a acumulação de riquezas materiais privilegiando a acumulação de conhecimentos sobre o mundo natural - e também sobrenatural - com o fim de sobrevivência, os quais são transmitidos oralmente de geração a geração, constituindo um legado cultural e coletivo indispensável ao equilíbrio do Planeta e à promoção da justiça socioambiental das presentes e futuras gerações.

E essa justiça é a base da teoria da equidade intergeracional que se "concentra na relação intrínseca que cada geração tem com outras, passadas e futuras, em quanto ao uso dos recursos naturais e culturais de nosso planeta" ${ }^{10}$, ou seja, todos somos usuários e devedores de cuidado.

São sociedades vulneráveis, pois suas condições sociais, étnicas, culturais, econômicas e educacionais são distintas da sociedade envolvente, e juridicamente hipossuficientes, especialmente em relação à indústria biotecnológica, o que demanda legislação específica e suporte governamental.

Enquanto a CDB não apresenta uma definição sobre o tema, a que não obstante pode ser extraída do artigo $8 j^{11}$, a aplicação desse instrumento jurídico no Direito brasileiro, em tanto que obrigações dos Estados Parte a serem desenvolvidas posteriormente, se encarregou de determinar um conceito próprio: informação ou prática individual ou coletiva de

\footnotetext{
${ }^{9}$ Dentro de uma perspectiva marxista (especialmente dos antropólogos neomarxistas), as culturas tradicionais estão associadas a modos de produção pré-capitalistas, próprios de sociedades em que o trabalho ainda não se tornou mercadoria, onde há grande dependência dos recursos naturais e dos ciclos da natureza, em que a dependência do mercado já existe, mas não é total. Essas sociedades desenvolveram formas particulares de manejo dos recursos naturais que não visam diretamente o lucro, mas a reprodução social e cultural; como também percepções e representações em relação ao mundo natural marcadas pela idéia de associação com a natureza e dependência de seus ciclos (DIEGUES, Antônio Carlos. 0 mito moderno da natureza intocável. 3a Ed. São Paulo: HUCITEC, 2001, p. 82.)

${ }^{10}$ BROWN WEISS, Edith: Un mundo justo para las nuevas generaciones. Madrid: Mundiprensa, 1999, p. 54.

${ }^{11}$ (...) conhecimento, inovações e práticas das comunidades locais e populações indígenas com estilo de vida tradicionais relevantes à conservação e à utilização sustentável da diversidade biológica (...). Disponível em: www.mma.gov.br/port/sbf/chm/doc/cdbport.pdf
} 
comunidade indígena ou de comunidade local, com valor real ou potencial, associada ao patrimônio genético ${ }^{12}$.

A CDB reforça a interdependência entre o conhecimento moderno e o tradicional e tenta conservar e defender este e seus titulares em razão dos acelerados processos de desaparecimento, da biopirataria e, sobretudo, porque "a fonte mais importante da criação de valor é particularmente o saber vivo, que está na base da inovação, da comunicação e da autoorganização criativa e continuamente renovada" ${ }^{13}$. Em síntese: "ironicamente, enquanto a sobrevivência cultural dos povos tribais e, em menor medida, os tradicionais se vê ameaçada, o mundo moderno reconhece e depende cada vez mais da sabedoria e perspectivas desses povos $^{\prime 14}$.

Os saberes tradicionais associados à biodiversidade significam ricos acervos em perigo de extinção, que devem ser protegidos principalmente em razão das políticas culturais homogeneizantes, da ausência de recursos estruturais para sua permanência, experiência, valorização e compreensão/identificação pelas novas gerações e, inclusive, pelas crescentes dificuldades de transmissão e continuidade que também decorrem dos efeitos da globalização cultural. Do mesmo modo, em razão à prática da biopirataria.

Sobre este aspecto, KAMAU ${ }^{15}$ defende a ideia de conhecimento tradicional disseminado, conceito baseado no atual estado de distribuição de conhecimentos tradicionais no Quênia, não obstante aplicável em qualquer outro país. Segundo o autor, o conhecimento tradicional disseminado é aquele que, resultado da disseminação irrestrita e livre do conhecimento tradicional sobre um longo período de tempo não está mais

\footnotetext{
$\overline{12}$ Artigo $77^{\circ}$, inciso II da Medida Provisória 2186-16 de 23 de agosto de 2001 que regulamenta o acesso ao patrimônio genético e conhecimento tradicional associado brasileiro. Disponível em: http://www.planalto.gov.br/ccivil_03/MPV/2186-16.htm. Acessado em abril de 2010.

${ }_{13}$ GORZ, André. O Imaterial. Conhecimento, Valor e Capital. São Paulo: Annablume, 2005, p. 20.

14 BROWN WEISS, Edith: Un mundo justo para las nuevas generaciones. Madrid: Mundiprensa, 1999, p. 266.

${ }^{15}$ KAMAU, Evanson Chege. "A implementação do artigo 8j da CDB, o problema do conhecimento tradicional disseminado e a experiência do Quênia". In: KISHI, Sandra Akemi Shimada; KLEBA, John Bernhard. Dilemas do acesso à biodiversidade e aos conhecimentos tradicionais. Direito, Política e Sociedade. Belo Horizonte: Método, 2009, p.171.
} 
sob o controle das populações tradicionais, é mantido de forma privada por entidades isoladas ou alienadas dessas comunidades que utilizam 0 conhecimento tradicional para auferir ganhos de maneira privada sem o reconhecimento das comunidades tradicionais e sua total exclusão na repartição de benefícios. Destarte, a consolidação normativa dessa idéia é perigosa;poderia legitimar a pilhagem ilegal dos saberes tradicionais.

Ao mesmo tempo, o advento da biotecnologia moderna sublimou o valor do bioconhecimento na busca por soluções - nos campos da medicina, alimentação e agricultura, energia, entre outros - para satisfazer as intermináveis necessidades da sociedade contemporânea. As comunidades tradicionais constituem importantes bioprospectores, posto que têm um conhecimento apurado acerca do terreno físico que habitam e dos recursos que nele se encontram, o que dista muito do que possam ter outros buscadores de tesouros genéticos.

\section{O PROCESSO CATALISADOR: A BIOTECNOLOGIA}

Assistimos a mudanças muito significativas no desenvolvimento da humanidade, assim como no estado das funções ambientais do Planeta. Mas talvez, nenhuma foi tão prometedora e preocupante como a revolução biotecnológica. As suas técnicas e resultados poderiam assegurar ou arrasar a segurança alimentaria mundial, encontrar bons resultados ou criar enfermidades, degradar ou conservar o meio ambiente, permitir o desenvolvimento dos países do Sul, possuidores de biodiversidade, ou obstruí-lo.

A biotecnologia é toda a aplicação tecnológica que utilize sistemas biológicos, organismos vivos ou seus derivados, para fabricar ou modificar produtos ou processos para utilização específica ${ }^{16}$. Não obstante, é necessário fazer uma distinção entre a biotecnologia tradicional, a realizada pelos povos tradicionais, e a biotecnologia moderna, executada pelos 'engenheiros da vida', utilizando a expressão de RIFKIN ${ }^{17}$.

\footnotetext{
${ }^{16}$ Artigo 2.2 da CDB.

${ }^{17}$ RIFKIN, Jeremy. El siglo de la biotecnología. Barcelona: Crítica-Marcondo, 1999, p.30.
} 
A biotecnologia é uma técnica que vem sendo utilizada pelo homem há muitos séculos e permitiu o desenvolvimento da humanidade desde diferentes aspectos. Mediante técnicas tradicionais de fermentação que se utilizam de microorganismos (fungos e bactérias), foram produzidos alimentos básicos como o pão, o queijo, o iogurte, o vinho e a cerveja. Também, foi o método por excelência utilizado por campesinos para o melhoramento vegetal e animal, mediante sucessivas seleções genéticas dentro de uma mesma espécie, com vistas a desenvolver produtos alimentícios de melhor qualidade protéica, durabilidade, tamanho, colheitas mais rentáveis e resistentes a pragas e agentes externos ${ }^{18}$. Esta classe de biotecnologia, intimamente relacionada com o saber das comunidades tradicionais também logrou obter dos extratos de plantas, diversas medicinas (a penicilina, por exemplo).

A biotecnologia moderna já é o principal foco do mercado mundial do presente século, juntamente com as tecnologias da informação e comunicação. Consiste no resultado da técnica da engenharia genética: a atividade de manipulação de moléculas de ADN recombinante, ou seja, a agrupação artificial de moléculas ou partes de moléculas de ADN que não se encontram juntas na natureza e que se convertem numa nova combinação ou nível de variação, gerando assim os organismos vivos modificados $(\mathrm{OVMs})^{19}$. Além da indústria agrícola, tem exponencial atuação na farmacêutica, cosmetológica, química e ambiental.

Assim é que os recursos genéticos e os saberes tradicionais, seja de como operar/desenvolver um produto ou coletar um recurso genético, adquirem especial relevância (econômica, científica e social) nesse novo Gênesis. São a matéria prima da indústria biotecnológica.

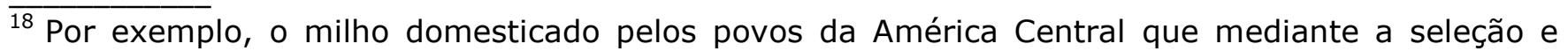
cruzamento entre diversas linhagens desenvolveram espécies melhoradas que são tolerantes à seca e às altas temperaturas, resistentes a larvas e insetos daninhos e que possuem um melhor nível de rendimento de grãos.

${ }^{19}$ Os casos mais conhecidos de OVMs são a soja RR (Roundup Ready, fabricada pela Monsanto) que é o resultado de uma espécie de soja silvestre, na qual foi introduzida o gene de uma bactéria denominada Agrobacterium sp resistente ao agroquímico mais eficiente (o glifosato, também fabricado pela Monsanto) para combater as pragas que crescem nas plantações de soja; e o milho BT, produzido pela Novartis, que recebeu um gene da bactéria Bacillus Thuringiensis (BT) resistente aos insetos que arruínam as plantações dessa cultura.
} 


\section{OS INSTRUMENTOS NORMATIVOS INTERNACIONAIS PARA O PATRIMÔNIO CULTURAL IMATERIAL}

\section{A OCORRÊNCIA NOS CONHECIMENTOS TRADICIONAIS}

O denominado Patrimônio Cultural Imaterial (adiante PCI) pode ser qualificado como um conjunto de mentefatos de presumida espontaneidade e autenticidade, expressos ou materializados sob diversas e distintas formas que recebem a rotulação patrimonial. São informações registradas em materiais humanos ou tecnológicos que devem ser transmitidas em razão de seu interesse público intergeracional.

A própria definição de patrimônio contempla, em sentido figurado, a noção de riqueza, abundância, profusão. E o que se pode perceber na atualidade é exatamente esse uso desenfreado do desejo de patrimonializar, em determinar, quase sempre sem o apoio científico e a consulta pública, certos artefatos ou mesmo mentefatos como bens de guarda permanente e legáveis que devem ser destinados, como herança, às futuras gerações. Essa assertiva, embora ingênua e redutora da problemática, não deixa de ser verdadeira e merecer uma reflexão.

Assim, qualifica-se o PCI como autêntico e espontâneo, vivo, constantemente recriado e reexperimentado que se transforma em registro mnemotécnico, em cultura transmitida principalmente através da oralidade, tendo a mente humana o seu principal repositório e os órgãos e membros humanos como os principais instrumentos de efetivação material, notadamente compartilhada, retro-alimentada e redimensionada coletivamente entre as gerações. Dessa forma, o patrimônio cultural é um elemento essencial à existência, às identidades coletivas, é base de crenças, tradições e costumes de distintos grupos humanos.

A Convenção para a salvaguarda do patrimônio cultural imaterial de 2003 define o PCI como as práticas, representações, expressões, conhecimentos e técnicas - junto com os instrumentos, objetos, artefatos e lugares culturais que lhes são associados - que as comunidades, os grupos 
e, em alguns casos, os indivíduos reconhecem como parte integrante de seu patrimônio cultural (artigo 2.1).

Em verdade, o patrimônio imaterial é o saber, o conhecimento, o bem intangível armazenado na mente que se manifesta em produtos diversos (danças, ritos, artesanatos, medicinas, culturas agrícolas) e se transmite, via de regra, oralmente.

Entre outras expressões, o PCI se manifesta nos conhecimentos e práticas relacionados à natureza e ao universo (artigo 2.2 da Convenção. A página web da Unesco ${ }^{20}$, relativa ao $\mathrm{PCI}$, apresenta a esfera de entendimento desse campo: a sabedoria ecológica tradicional, os conhecimentos indígenas, a etnobiologia, a etnobotânica, a etnozoologia, os sistemas de cura tradicionais e sua farmacopéia, rituais, usos alimentícios, entre outros. Deste modo, os saberes tradicionais associados à biodiversidade desfrutam de mais um mecanismo de proteção jurídica em âmbito internacional.

Sem embargo, na lista representativa ${ }^{21}$ do patrimônio cultural imaterial não consta nenhum PCI relacionado ao uso da biodiversidade por comunidades tradicionais.

\section{PROTEÇÃO INTERNACIONAL: A CONVENÇÃO SOBRE A SALVAGUARDA DO PATRIMÔNIO CULTURAL IMATERIAL}

A proteção internacional do patrimônio cultural tem suas origens tão logo decorrida a Segunda Guerra Mundial, com a Constituição da UNESCO, em 4 de novembro de 1946.

Durante a segunda metade do século $X X$, uma intensa atividade legislativa consolidou a proteção jurídica internacional do patrimônio cultural, o que de certa forma foi refletida e difundida nos direitos internos dos países membros da ONU. Vale recordar a Convenção 169 da OIT sobre

\footnotetext{
$\overline{20}$ http://www. unesco.org/culture/ich/index.php?pg $=56$.

${ }^{21}$ Esta lista é o objeto do artigo 17 da Convenção e constitui uma medida de salvaguarda para assegurar maior visibilidade do patrimônio cultural imaterial, aumentar o grau de conscientização de sua importância, e propiciar formas de diálogo que respeitem a diversidade cultural. Disponível em: http://www.unesco.org/culture/ich/index.php?pg=00011\&type=00002\&inscription=00003
} 
povos indígenas e tribais em países independentes de 1989, a Convenção para a salvaguarda do patrimônio mundial, cultural e natural de 1972 e a Recomendação da UNESCO sobre a salvaguarda da cultura tradicional e popular de 1989.

Não obstante, o patrimônio cultural entendido como imaterial ou intangível tão somente recebe proteção em instrumento jurídico internacional próprio no ano de 2006, com a entrada em vigor (20 de abril), da Convenção sobre a salvaguarda do patrimônio imaterial, aprovada em 17 de outubro de 2003. A Convenção busca criar as condições necessárias para a identificação, salvaguarda e conservação, difusão e proteção do PCI interconectando-o com os patrimônios culturais materiais e naturais.

A dialética contemporânea que promove, por um lado, as inúmeras possibilidades de diálogos culturais e, por outro, a tirania de uma cultura sobre a outra, é prevista pela Convenção na adoção de um instrumento de caráter multilateral e juridicamente vinculante para a salvaguarda do PCI.

Os objetivos da Convenção são a salvaguarda ${ }^{22}$, o respeito ao $\mathrm{PCI}$ das comunidades, grupos e indivíduos, a sensibilização no plano local, nacional e internacional em relação à importância do PCI e a cooperação e assistência internacionais. Esses objetivos permitem a conservação da riqueza da diversidade humana e a promoção da criatividade, bem como ajusta o objetivo/princípio do desenvolvimento sustentável ao patrimônio cultural.

Ainda que constitua um instrumento jurídico vinculante, seu cumprimento está condicionado ao tipo de disposições contidas em seu texto - composto por normas flexíveis (soft law), próprias dos tratados internacionais multilaterais - que evita utilizar palavras ou expressões que manifestam uma obrigação de resultado, mas sim de comportamento. Assim, recorre a expressões como 'empreenderá esforços' e 'se empenhará'

\footnotetext{
$\overline{22}$ Entende-se por salvaguarda as medidas que visam garantir a viabilidade do patrimônio cultural imaterial, tais como a identificação, a documentação, a investigação, a preservação, a proteção, a promoção, a valorização, a transmissão - essencialmente por meio da educação formal e nãoformal - e revitalização deste patrimônio em seus diversos aspectos. (artigo 2.3 da Convenção sobre a salvaguarda do patrimônio cultural imaterial)
} 
em se tratando das medidas a serem tomadas no ordenamento interno dos Estados Parte.

Se, por uma parte, estas características respeitam as capacidades particulares de cada Estado-Membro, por outra, podem fragilizar o conteúdo obrigatório da Convenção, de caráter mais preventivo que repressivo e composto mais de recomendações e compromissos que de obrigações. Esse tipo de normativa tem respaldo em uma conduta éticopolítica, potencializada por uma expectativa positiva de cumprimento por todos os Estados, em um ambiente semelhante ao efeito dominó e em nossa opinião, passível de aplicação, observada a ética na conduta dos Estados.

Importante mencionar os mecanismos de aplicação dos objetivos da Convenção em nível nacional. Os Estados Parte deverão adotar medidas de salvaguarda do PCI, tais como identificar e definir os diversos elementos do PCI em seus territórios, inventariar esse patrimônio, adotar políticas de promoção da função do PCI, criar organismos capazes de salvaguardá-lo, entre outras. Ademais, deverá empreender esforços na educação, conscientização e fortalecimento de capacidades e possibilitar a participação das comunidades, grupos e indivíduos na salvaguarda do PCI.

Possui órgãos institucionais próprios - Assembléia Geral dos Estados Partes, Comitê Intergovernamental para a Salvaguarda do PCI e um Secretariado. Esses órgãos, ademais de suas funções específicas, têm a competência de desenvolver as disposições da Convenção e de orientar as Partes em seus trabalhos de execução ou, em outras palavras, a incumbência de proporcionar vitalidade e continuidade aos propósitos do texto.

\section{A SALVAGUARDA DO PCI COMO PREOCUPAÇÃO COMUM DA HUMANIDADE}

O reconhecimento internacional do princípio da preocupação comum da humanidade se concretizou na Rio/92. Entretanto, já havia sido utilizado na 
Resolução $43 / 53^{23}$ da Assembléia Geral das Nações Unidas sobre a proteção do clima mundial para as presentes e futuras gerações. Por sua vez, a Convenção sobre a salvaguarda do patrimônio cultural imaterial introduz o princípio em seu preâmbulo ${ }^{24}$.

O referido princípio possui um vínculo estreito com outro anteriormente utilizado no Direito Internacional: o do patrimônio mundial da humanidade ou patrimônio comum da humanidade ${ }^{25}$. Nesse sentido, interessa destacar que:

a noção de patrimônio comum da humanidade implica o reconhecimento da existência de certos interesses comuns e superiores que ultrapassam os objetivos imediatos e particulares dos Estados e comporta assim mesmo, a idéia de uma participação da Comunidade Internacional na gestão do patrimônio e no reparto eqüitativo de seus recursos, excluindo toda apropriação ou reclamação unilateral de soberania ${ }^{26}$.

A adoção do princípio da preocupação comum da humanidade originou-se principalmente dos problemas que suscitavam o do patrimônio comum da humanidade ${ }^{27}$ utilizado anteriormente, em matéria de recursos biológicos, pelo Compromisso internacional sobre recursos fitogenéticos e pelo projeto de Convenção internacional sobre diversidade biológica, proposto pela organização não governamental União Mundial para a Natureza (UICN).

Estes instrumentos, baseados na noção de patrimônio comum da humanidade, inspiravam a persistência pela internacionalização dos recursos biológicos, o que implicaria na liberdade de acesso de seus componentes tangíveis e intangíveis (recursos genéticos e conhecimentos tradicionais).

\footnotetext{
23 Doc. A/RES/43/53 de 6 de dezembro de 1988. Esta Resolução reconheceu que as mudanças climáticas constituem uma preocupação comum da humanidade, dado que o clima é um elemento essencial da vida na terra. Posteriormente, este conceito foi reafirmado na Resolução 44/207. Disponível em: http://www.un.org/documents/ga/res/43/a43r053.htm

24 "Consciente da vontade universal e da preocupação comum de salvaguardar o patrimônio cultural imaterial da humanidade".

${ }^{25}$ A expressão está presente, por exemplo, no preâmbulo da Convenção para a proteção do patrimônio mundial, cultural e natural de 1972.

${ }^{26}$ ALTEMIR, Antonio Blanc. El Patrimonio Común de la Humanidad: Hacia un régimen jurídico internacional para su gestión. Barcelona: Bosch, 1992, p. 31.

27 SALOM sustenta que "a principal diferença entre o patrimônio comum da humanidade e a preocupação comum à humanidade reside na exploração dos recursos, já que o regime de patrimônio comum proíbe a apropriação dos recursos qualificados como patrimônio comum, enquanto que sob o regime de preocupação comum não existe proibição de apropriação em nome dos direitos soberanos dos Estados" (SALOM, José Roberto Pérez. "El derecho internacional y el estatuto de los recursos genéticos". In: Anuario de Derecho Internacional. Vol. XIII. Pamplona: Universidad de Navarra, 1997, p. 101).
} 
Consequentemente, a utilização deste conceito seria incompatível com a faculdade dos Estados de regular o acesso aos recursos genéticos e conhecimentos tradicionais situados em suas jurisdições, manifestada no artigo $15 \S 1^{\circ}$ da CDB, e portanto de aceitá-lo ou denegá-lo, desviando, desta forma, qualquer possibilidade de livre acesso ou intervenção externa. No entanto, com o acolhimento do conceito de preocupação comum da humanidade, o país de origem do recurso genético e do saber tradicional delimitará a fonte geográfica exata do acesso, a titularidade e, consequentemente, terá legitimidade para reclamar e participar de forma justa e eqüitativa nos benefícios gerados do uso, objetivo econômico da CDB.

A Convenção sobre a salvaguarda do patrimônio cultural imaterial seguiu a nova tendência e contemplou a idéia de preocupação comum da humanidade, o que estabelece compatibilidade com a CDB no relativo à possibilidade de nacionalizar os recursos biológicos e os saberes atrelados a seu uso. Entendemos que o Brasil, ao adotar a MP 2.186/2001, compreende como bens nacionais os recursos genéticos e conhecimentos tradicionais brasileiros.

\section{OS INSTRUMENTOS NORMATIVOS NACIONAIS: A MEDIDA PROVISÓRIA 2.186/2001 E A CONSTITUIÇÃO FEDERAL DE 1988}

Afinal, o que temos em comum eu (Mário de Andrade, paulistano) e um seringueiro do Acre?

A indagação de Mário de Andrade revela a inquietação ainda contemporânea com os registros humanos, os artefatos e mentefatos que consolidam a existência de uma teia de informações coletivas que configuram a memória social transgeracional.

Os pouco mais de 500 anos de Brasil escrevem uma estimável diversidade cultural, o reflexo da cultura sempre viva, expressada em um patrimônio material e imaterial e revelada em edificações, monumentos, paisagens, costumes, conhecimentos e práticas tradicionais de comunidades tradicionais.

A política de preservação do patrimônio cultural é hoje uma realidade. $O$ processo de consolidação, iniciado no Brasil da década de 30 do século $\mathrm{XX}$, com o modernista Mário de Andrade (Decreto-lei $N^{\circ} 25 / 37$, a Lei Andradina), culmina 
na Constituição Federal de 1988 que estabelece ao Poder Público e à sociedade o dever de preservar o patrimônio cultural e descreve quais bens o constituem ${ }^{28}$.

Instituída às pressas pelo Poder Executivo Federal, em razão de um contrato controverso de acesso ao patrimônio genético amazônico entre a Bioamazônia e a Novartis Pharma AG, em maio de 2000, a MP 2186-16 (MP) é a legislação emergencial que regula o acesso ao patrimônio genético situado no território nacional, na plataforma continental e na zona econômica exclusiva; a proteção e o acesso ao conhecimento tradicional associado; a repartição de benefícios e o acesso e transferência de tecnologias. Em verdade, implementa a cartilha ditada nos artigos $15 \$ 1^{\circ}$ e $8 \mathrm{j}$ da $C D B$, ou seja, que os Estados devem instituir legislação que promova e direcione o acesso ao patrimônio genético e aos conhecimentos tradicionais.

Os artigos $8^{\circ}$ e $9^{\circ}$ tratam da proteção ao conhecimento tradicional associado das comunidades tradicionais. $O$ artigo $8^{\circ}$ protege 0 conhecimento dessas comunidades contra a utilização e exploração ilícita. Ademais, confere às comunidades o direito de decidir sobre o uso de seus conhecimentos e os reconhece como patrimônio cultural brasileiro.

Por sua vez, 0 artigo $9^{\circ}$ estabelece os direitos das comunidades: ter indicada a origem do acesso ao conhecimento em publicações, utilizações, explorações e divulgações; impedir terceiros não autorizados de utilizar, realizar testes, pesquisas ou exploração relacionadas ao conhecimento tradicional associado; divulgar, transmitir ou retransmitir dados ou informações que integrem ou constituam o conhecimento e perceber benefícios derivados da exploração econômica.

Essa legislação ofereceu por primeira vez ao Estado Brasileiro, depois de 500 anos de apropriação indevida, sem anuência e participação nos benefícios, a possibilidade de evitar ou prevenir essa prática desprezível da biopirataria que prejudicou sobretudo comunidades amazônicas.

O artigo $16 \S 9$ da MP determina que a autorização de acesso da comunidade tradicional está adstrita à anuência prévia, termo utilizado

\footnotetext{
${ }^{28}$ As formas de expressão; os modos de criar, fazer e viver; as criações científicas, artísticas e tecnológicas; as obras, objetos, documentos, edificações e demais espaços destinados às manifestações artístico-culturais; os conjuntos urbanos e sítios de valor histórico, paisagístico, artístico, arqueológico, paleontológico, ecológico e científico (artigo 216 CF/88).
} 
equivocadamente ${ }^{29}$ pela MP e que corresponderia ao princípio do consentimento prévio informado apontado na CDB. O consentimento prévio informado é uma espécie de pré-contrato de concessão, que é a base regulamentária ou a medida de controle do acesso aos recursos genéticos e permite ao provedor do recurso genético e, ou dos conhecimentos tradicionais associados negociar, em melhores condições, os termos do contrato de acesso e a repartição dos benefícios. Permite a troca de informações necessárias (sobre o uso, os métodos de coleta e o tratamento dos dados, os benefícios a serem gerados e os meios de recompensa, o lugar de origem do conhecimento, etc.) e a ampla participação na concordância ou não dos membros da comunidade.

Interessa destacar que, independentemente de haver ou não perspectivas comerciais, toda pesquisa científica que envolver o acesso a conhecimento tradicional associado, deverá ser autorizada pelo Conselho de Gestão do Patrimônio Genético (CGEN), órgão de caráter deliberativo e normativo criado pela $\mathrm{MP}$, vinculado ao Ministério do Meio Ambiente. A anuência prévia das comunidades tradicionais, quando o acesso envolver seus conhecimentos e/ou componente do patrimônio genético situado em áreas sob sua posse ou propriedade, está investida de critérios estabelecidos em Resoluções do CGEN ${ }^{30}$.

De certa forma, essas normas já configuram um meio de proteção dos conhecimentos tradicionais, visto que conectam a autorização do acesso ao consentimento prévio informado, principal instrumento de garantia da repartição dos benefícios e do amparo à hipossuficiência das comunidades tradicionais que deverão ser assessoradas pelo CGEN.

Por último, cabe referir a proteção constitucional dispensada no artigo 216 sobre os elementos que constituem o patrimônio cultural e os bens de natureza material e imaterial. Os conhecimentos tradicionais se ajustam ao inciso II: os modos de criar, fazer e viver. Em palavras de Inês Soares ${ }^{31}$ :

\footnotetext{
${ }^{29} \mathrm{KISHI}$, Sandra Akemi Shimada. "Consentimento prévio informado no Brasil". In: KISHI, Sandra Akemi Shimada; KLEBA, John Bernhard. Dilemas do acesso à biodiversidade e aos conhecimentos tradicionais. Direito, Política e Sociedade. Belo Horizonte: Método, 2009, p 193.

30 Resoluções 5, 6, 9 e 12 do CGEN. Disponível em:

http://www.mma.gov.br/sitio/index.php?ido=conteudo. monta\&idEstrutura $=222 \&$ idConteudo $=9074$ \&idMenu=9827. Acessado em abril de 2010.

31 SOARES, Inês Virgínia Prado. Direito ao (do) Patrimônio Cultural Brasileiro. Belo Horizonte: Forum, 2009.
} 
por isso, os conhecimentos tradicionais são considerados pelo ordenamento jurídico brasileiro como gênero cultural, que abriga elementos culturais (pesca, caça, saberes sobre propriedades medicinais de uma planta etc.) com potencialidade de serem bens culturais brasileiros. No entanto, vale destacar que, além do valor de referência ligado à seara patrimonial, os conhecimentos tradicionais são portadores de outros valores e interesses, também relevantes juridicamente, inclusive para a preservação de seus elementos: de manifestação cultural, de exercício de direitos intelectuais, de direito ao território em que vivem as comunidades tradicionais, entre outros.

\section{OUTROS INSTRUMENTOS DE PROTEÇÃO: INTIMIDANDO A BIOPIRATARIA}

\section{OS DIREITOS DE PROPRIEDADE INTELECTUAL E O SISTEMA SUI}

GENERIS

O Direito reconhece e regula a propriedade intelectual, o direito de autoria e cria mecanismos para o reconhecimento e a tangibilidade de idéias advindas da ciência e tecnologia, mas é tímido em relação à criação cultural coletiva.

Os direitos de propriedade intelectual são um sistema legal que conferem direitos de exclusividade aos indivíduos e às empresas por suas inovações ou invenções. São direitos distintos aos direitos de propriedade real que vislumbram objetos materiais, pois protegem elementos imateriais advindos da criatividade intelectual e estão limitados pelo tempo. O titular de um direito de propriedade intelectual tem o direito exclusivo e de não permitir que terceiros utilizem seu invento.

Antes da entrada em vigor da CDB vigorava o princípio do livre acesso. Este instrumento jurídico, especialmente mediante o artigo 15, fechou as portas do hothouse e se apoiou no princípio da soberania dos Estados sobre seus recursos biológicos em parceria com o da preocupação comum da humanidade, cuja principal conseqüência jurídica é a faculdade dos Estados de regular e dispor de um regime próprio de acesso a recursos genéticos e saberes tradicionais que, entre outros elementos, assegure a titularidade nacional. Por conseguinte, 
assume também a titularidade das comunidades tradicionais sobre seus conhecimentos e afasta a antiga idéia de domínio público.

Neste longo período de vazios normativos sobre acesso ao patrimônio genético e saberes tradicionais, as coletas e explorações estiveram desprovidas de um marco legal adequado e a falta de regulamentação desta conduta facilitou uma insustentável e extensa subtração, cujos resultados geraram incontáveis perdas econômicas aos Estados de origem destes recursos, aos detentores de conhecimentos tradicionais e também foi fator de auxílio à degradação de ecossistemas e à diminuição ou extinção de espécies e sistemas sociais tradicionais, incluídos os saberes.

O sistema sui generis tem como alicerce a titularidade dos conhecimentos tradicionais pelas comunidades. Refere-se a uma possível modalidade de direitos de propriedade intelectual (DPI), alternativo e ainda não definido nem regulamentado.

Esta modalidade foi projetada visto que o sistema de direitos de propriedade clássico não apresenta uma resposta adequada de proteção do conhecimento tradicional associado à biodiversidade. Primeiro, porque ampara invenções eminentemente individuais e são de caráter privativo e os conhecimentos tradicionais têm uma natureza coletiva, de interesse público e intergeracional. Segundo, porque os registros são custosos para serem satisfeitos por estas comunidades, além de estarem limitados pelo tempo, o que afetaria os propósitos intergeracionais que tais saberes significam a estas sociedades. Também, o elemento novidade não está presente já que esses conhecimentos, ainda que não absolutamente, são frequentemente milenários.

Para Vandana Shiva ${ }^{32}$, há duas restrições principais vinculadas ao conceito de inovação segundo o Acordo sobre aspectos dos direitos de propriedade intelectual relacionados ao comércio (ADIPC), regime internacional de proteção do DPI. A primeira se deriva da afirmação (no preâmbulo) de que os DPI são direitos privados e esta definição excluiria todas as formas de conhecimento, idéias e inovações desenvolvidas no âmbito do 'território coletivo intelectual'. A segunda se refere ao fato dos DPI somente reconhecerem o conhecimento e a inovação quando geram lucros e não quando cumprem uma função social, circunstância marcadamente presente nas comunidades tradicionais. Segundo o

\footnotetext{
32 SHIVA, Vandana. Biopiratería. El saqueo de la naturaleza y del conocimiento. Barcelona: Icaria, 2001, p. 33.
} 
artigo 27.1, a inovação tem que ser suscetível de aplicação industrial para ser considerado um DPI.

Um sistema sui generis de proteção intelectual dos conhecimentos tradicionais deveria ser reconhecido tanto na política nacional de biodiversidade como na lei nacional sobre acesso a recursos genéticos, instrumentos a serem desenvolvidos nos direitos internos dos países para a implementação dos objetivos da CDB. Sem embargo, por se tratar de um tema quase interdito, dado a potência do poder transnacional e o interesse econômico, poucos Estados tratam o assunto.

O Regime comum sobre propriedade intelectual da Comunidade Andina ${ }^{33}$, por exemplo, considera nula a patente que não apresenta a cópia do documento que acredite a licença ou autorização de uso dos conhecimentos tradicionais das comunidades indígenas afroamericanas ou locais dos Países Membros, quando os produtos ou processos objetos de proteção são obtidos ou desenvolvidos a partir desses conhecimentos ${ }^{34}$. A Lei de biodiversidade da Costa Rica ${ }^{35}$ prevê um registro ou inventário dos conhecimentos tradicionais que as comunidades solicitam proteger, ademais da definição de um processo participativo com as comunidades tradicionais para determinar a natureza, os alcances e requisitos desses direitos.

A Decisão 16 da sétima Conferência das Partes na $\mathrm{CDB}^{36}$ aponta alguns elementos que poderiam constituir o sistema sui generis. Entre eles, o reconhecimento das leis consuetudinárias das comunidades tradicionais, um procedimento e conjunto de requisitos que conduzam o consentimento prévio informado, um sistema de registro dos conhecimentos tradicionais e autoridade competente para administrar os assuntos administrativos sobre a proteção.

O domínio conjunto dos direitos de propriedade intelectual das comunidades tradicionais e outros atores (empresas, comunidade científica, entre outros) no desenvolvimento e/ou comercialização de produtos que vinculam recursos genéticos e conhecimento tradicional associado também é uma alternativa. Essa possibilidade constitui um dos benefícios monetários previstos

\footnotetext{
33 Decisão 486, de 14 de setembro de 2000. Disponível em: http://www.comunidadandina.org/normativa/dec/D486.htm.

${ }^{34}$ Artigo $75(\mathrm{~h})$.

35 Lei No 7788, de 4 de março de 1998. Disponível em: http://www.conarefi.ucr.ac.cr/LeyBiodiversidad.htm

${ }_{36} \mathrm{UNEP} / \mathrm{CBD} / \mathrm{COP} / \mathrm{DEC} / \mathrm{VII} / 16$. Article $8(\mathrm{j})$ and related provisions, p. 35-36. Disponível em: https://www.cbd.int/doc/decisions/cop-07/cop-07-dec-16-en.pdf.
} 
nas Diretrizes de Bonn ${ }^{37}$, entretanto que meio para repartir justa e equitativamente os benefícios derivados do uso dos recursos genéticos e conhecimentos tradicionais, objetivo econômico da CDB.

Ademais, é recorrente o uso da expressão sistema sui generis. Portanto, em primeiro lugar deve-se observar o significado e o porquê do uso dessa expressão. De origem latina, significa "único em seu gênero". Assim sendo, o sistema deverá afastar os direitos existentes para proteger inventos individuais, inovadores, típica e unicamente comerciais (patentes, segredos comerciais, etc.).

Nesse sentido, é necessário levar em consideração a forma como esse conhecimento é construído: tradicionalmente, transmitido por via oral entre gerações com cultura e organização próprias e residentes em locais determinados. Deste modo, o sistema deve favorecer o intercâmbio de informações, pilar da sua existência, e não congelá-lo, para permitir e promover sua permanência.

\section{ESPECIAL REFERÊNCIA AOS REGISTROS DE CONHECIMENTOS} TRADICIONAIS

Instituído pelo Decreto $\mathrm{n}^{\circ} 3.551$, de 4 de agosto de 2000, o Programa Nacional do Patrimônio Imaterial ${ }^{38}$ (PNPI), vinculado ao IPHAN, estabelece a política nacional de identificação, reconhecimento, salvaguarda e promoção da dimensão imaterial do patrimônio cultural.

Um dos instrumentos de política do PNPI são os registros ${ }^{39}$, um instrumento legal para o reconhecimento e valorização do patrimônio cultural imaterial brasileiro, regulamentado pela Resolução $n^{\circ} 1$ de 3 de agosto de $2006^{40}$. Os bens quando registrados são inscritos nos Livros de Registro dos Saberes, das Celebrações, das Formas de Expressões e dos Lugares.

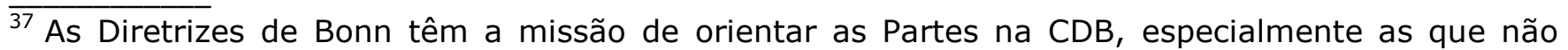
possuem normativas nacionais de acesso a recursos genéticos, na celebração de contratos de acesso ao patrimônio genético e conhecimentos tradicionais. Doc. UNEP/CDB/COP/6/20, de 23 de setembro de 2002. Informe de la sexta reunión de la Conferencia de las Partes en el Convenio sobre la Diversidad biológica, p. 286. Disponível em : http://www.cbd.int/doc/meetings/cop/cop-06/official/cop-06-20-es.pdf

38 Disponível em: http://portal.iphan.gov.br/portal/baixaFcdAnexo.do?id=201.

${ }^{39} \mathrm{Em}$ verdade, não é a simples guarnição de registros tampouco das identidades absolutas. É uma satisfação, um anseio; uma transmissão da necessidade de comunicação, transmissão, transformação e permanência. Um instrumento ao conhecimento, à reflexão e à evolução.

${ }^{40}$ Disponível em: http://portal.iphan.gov.br/portal/baixaFcdAnexo.do?id=690.
} 
A ausência de um registro formal resulta uma dupla preocupação: a fragilidade de permanência e transmissão e a consequente ameaça de extinção iminente. Também, convêm lembrar a tradição do livre acesso à riqueza natural e cultural associada - ou pirataria - restringida depois da entrada em vigor da CDB. No entanto, esta pilhagem, todavia um costume avalizado dado à ineficiência das medidas e instrumentos jurídicos pertinentes, igualmente pode contribuir para a extinção, ao menos como PCI.

Experiências com registros foram concretizadas. Vale memorar a Farmacopéia Popular do Cerrado, envolvendo nove espécies de plantas e seus usos como medicamentos, cosméticos.

O referido instrumento de política do PNPI, em se tratando de conhecimentos tradicionais, poderia ser gerenciado pelo CGEN, já que este órgão é responsável pela administração nacional do acesso a recursos genéticos e conhecimentos tradicionais. Nesse sentido, seria oportuno a realização de um inventário nacional.

\section{CONSIDERAÇÕES FINAIS}

O homem produz, capta, guarda e transmite conhecimento em sua trajetória. Cria, modifica, atualiza seus pensamentos, desejos, atividades. Inova! Registra! Patrimonializa! Forma a cultura, a sua história. Um tanto se perde no caminho, outro é anotado, preservado, transmitido. Esse conhecimento necessita suportes para sustentar a memória coletiva ou social dos acontecimentos, o que ampara as relações humanas de hoje, ontem, amanhã.

Os conhecimentos tradicionais das comunidades tradicionais associados à biodiversidade são um patrimônio, uma herança de soberana importância à sobrevivência da vida na Terra, especialmente porque essas comunidades são as conhecedoras por excelência do meio em que habitam, da biodiversidade e das melhores formas de conservá-la e utilizá-la sustentavelmente. Promovem o adequado desenvolvimento sustentável.

Acreditamos que esse conhecimento não é de domínio público, tampouco pode ser entendido como legado da humanidade no sentido de patrimônio comum da humanidade, precisamente em razão à adoção - na CDB e na Convenção de 2003 - do princípio da preocupação comum da humanidade, que exclui a possibilidade de intervenção externa, a internacionalização dos recursos 
genéticos e conhecimentos tradicionais. E o Estado brasileiro assumiu essa idéia afirmando que o conhecimento tradicional associado ao patrimônio genético integra o patrimônio cultural brasileiro (art. $8^{\circ} \S 2^{\circ}$ da MP 2.186-16 de 2001). É consensual o caráter de interesse público, mas não é ou não deveria ser um patrimônio público.

Por que tratar como de domínio público, um conhecimento pertencente a um grupo determinado, que analisou, experenciou, aplicou, registrou e transmitiu? Quiçá a equivocada ideia de que essa espécie de conhecimento não configura ciência em seu sentido estrito suporte tal premissa.

Portanto, é necessário assegurar direitos de propriedade às comunidades detentoras de saberes associados à biodiversidade, sobretudo em função de sua situação hipossuficiente nas possíveis relações contratuais de uso desses conhecimentos, da prática da biopirataria e das dificuldades de transmissão que decorrem dos efeitos da globalização cultural.

Assim sendo, a idéia de um sistema sui generis de direitos de propriedade intelectual deve preconizar o consentimento prévio informado, pois esse instrumento pré-contratual pode garantir a concordância ou não da comunidade e a distribuição de benefícios no caso de aproveitamento comercial. Ademais, deve observar e instituir métodos que resguardem a hipossuficiência das comunidades e que permitam a recriação e o livre intercâmbio entre comunidades e gerações.

Urge estabelecer critérios que garantam a continuidade cultural constituída, entre outros elementos, pelo saber, pela imaginação e inteligência tradicional. $O$ princípio da preocupação comum da humanidade constitui um primoroso mecanismo para o adequado tratamento, além dos direitos de propriedade e dos suportes que avalizam a sustentabilidade informacional.

Por fim, é importante não olvidar, seguindo Gorz, que o capitalismo moderno, centrado sobre a valorização de grandes massas de capital fixo material, é cada vez mais rapidamente substituído por um capitalismo pósmoderno centrado na valorização de um capital dito imaterial, qualificado também de "capital humano", "capital do conhecimento" ou "capital da inteligência" ${ }^{41}$.

$\overline{41}$ GORZ, André. O Imaterial. Conhecimento, Valor e Capital. São Paulo: Annablume, 2005, p.16. 


\section{REFERÊNCIAS}

ALTEMIR, Antonio Blanc. El Patrimonio Común de la Humanidad: Hacia un régimen jurídico internacional para su gestión. Barcelona: Bosch, 1992.

BROWN WEISS, Edith: Un mundo justo para las nuevas generaciones. Madrid: Mundiprensa, 1999, p. 54.

COMUNIDADE ANDINA. DECISIÓN 486. Disponível em: http://www.comunidadandina.org/ingles/normativa/D486e.htm.

DA CUNHA, Manuela Carneiro. "Populações tradicionais e a Convenção da Diversidade Biológica". In: Estudos Avançados. Vol. 13. №. 36. São Paulo: maio/agosto de $1999 . \quad$ Disponível em: http://www.scielo.br/scielo.php?script=sci_arttext\&pid=S010340141999000200008\&lang=pt

DIEGUES, Antônio Carlos e ARRUDA, Rinaldo S, V. (orgs.) Saberes Tradicionais no Brasil. Brasília: Ministério do Meio Ambiente; São Paulo: USP, 2001.

DIEGUES, Antônio Carlos. O mito moderno da natureza intocável. $3^{a}$ Ed. São Paulo: HUCITEC, 2001.

FLORES, Joaquín Herrera. Cultura y naturaleza: La construcción Del imaginário ambiental bio(sócio)diverso. In Hiléia. Revista de Direito Ambiental da Amazônia. Ano 2. Número 2. Janeiro-junho de 2004. Manaus: Edições Governo do Estado do Amazonas / Secretaria de Estado de Cultura / Universidade do Estado do Amazonas, 2004.

FROCHTENGARTEN, Fernando. "A memória oral no mundo contemporáneo". In: Estudos Avançados. Vol. 19. N. 55. São Paulo: setembro/dezembro, 2005. Disponível em:http://www.scielo.br/scielo.php?script=sci_arttext\&pid=S010340142005000300027\&lang=pt

GORZ, André. O Imaterial. Conhecimento, Valor e Capital. São Paulo: Annablume, 2005.

GUATTARI, Félix. As três ecologias. 6ª Ed. São Paulo: Papirus, 1997.

KAMAU, Evanson Chege. A implementação do artigo 8j da CDB, o problema do conhecimento tradicional disseminado e a experiência do Quênia. In: KISHI, Sandra Akemi Shimada; KLEBA, John Bernhard. Dilemas do acesso à biodiversidade e aos conhecimentos tradicionais. Direito, Política e Sociedade. Belo Horizonte: Método, 2009. 
KISHI, Sandra Akemi Shimada. "Consentimento prévio informado no Brasil". In: KISHI, Sandra Akemi Shimada; KLEBA, John Bernhard. Dilemas do acesso à biodiversidade e aos conhecimentos tradicionais. Direito, Política e Sociedade. Belo Horizonte: Método, 2009.

NAÇÕES UNIDAS. ASSEMBLÉIA GERAL. DOC. A/RES/43/53. Disponível em: http://www.un.org/documents/ga/res/43/a43r053.htm.

NAÇÕES UNIDAS. UNEP/CBD/COP/DECNII/16. Article 8(j) and related provisions. Disponível em: https://www.cbd.int/doc/decisions/cop-07/cop-07-dec-16-en.pdf.

NAÇÕES UNIDAS. UNEP/CDB/COP/6/20. Informe de la sexta reunión de la Conferencia de las Partes en el Convenio sobre la Diversidad biológica. Disponível em : http://www.cbd.int/doc/meetings/cop/cop-06/official/cop-06-20-es.pdf.

NAÇÕES UNIDAS. UNEP/CDB/COP/6/20, de 23 de setembro de 2002. Informe de la sexta reunión de la Conferencia de las Partes en el Convenio sobre la Diversidad biológica. Disponível em: http://www.cbd.int/doc/meetings/cop/cop06/official/cop-06-20-es.pdf.

RIFKIN, Jeremy. El siglo de la biotecnología. Barcelona: Crítica-Marcondo, 1999.

SALOM, José Roberto Pérez. "El derecho internacional y el estatuto de los recursos genéticos". In: Anuario de Derecho Internacional. Vol. XIII. Pamplona: Universidad de Navarra, 1997.

SANTILLI, Juliana. Socioambientalismo e Novos Direitos. São Paulo: Peirópolis, 2005.

SHIVA, Vandana. Biopiratería. El saqueo de la naturaleza y del conocimiento. Barcelona: Icaria, 2001.

SOARES, Inês Virgínia Prado. Direito ao (do) Patrimônio Cultural Brasileiro. Belo Horizonte: Forum, 2009.

SOUZA, Gabriela Coelho de, et. al. "Conhecimentos tradicionais: aspectos do debate brasileiro sobre a quarta dimensão da biodiversidade". In: KISHI, Sandra Akemi Shimada; KLEBA, John Bernhard. Dilemas do acesso à biodiversidade e aos conhecimentos tradicionais. Direito, Política e Sociedade. Belo Horizonte: Método, 2009. 